\title{
Enhancing Social Competence for Disadvantaged Youth in Pre-Vocational Education: Model Development Through Design-Based Research
}

\author{
Ida Kristina Kühn* \\ University of Bremen, Institute Technology and Education (ITB), \\ Am Fallturm 1, 28359 Bremen, Germany
}

Received: 04.08.2017; Accepted: 11.10.2017; Published: 21.12.2017

\begin{abstract}
This study investigates the enhancement of social competence for disadvantaged young people based on the example of the 'Werkschule Bremen' educational course. Theoretical approaches to social competence as a learning outcome are mainly based on the model of social information processing, although the meaning of both practical and experience-oriented approaches is constantly evolving. Taking the specific contextual conditions into account, this study combines qualitative and quantitative methods within the design-based research methodology in order to determine how a locationindependent didactical concept to enhance social competence could be created as well as which comparable impacts on the participants' social competence can be verified. The results show that a basic didactical concept is feasible, while the teaching and learning environment has a huge impact on the comparability. It is also clear that the students' motivation to participate depends on both their own and their teachers' interest as well as the teachers' capacity to facilitate safe relationships. As a core result, this study delivers a didactic model that is based on target-controlled experience-oriented learning environments on the practical side and the social information processing approach on the theoretical side.
\end{abstract}

Keywords: VET, Vocational Education and Training, Vocational Orientation, Vocational Preparation, Pre-vocational Education, Social Competence, Design-based Research

*Corresponding author: kristina.kuehn@uni-bremen.de

ISSN: $2197-8646$

http://www.ijrvet.net 


\section{Introduction}

Social competence has a significant impact on personal well-being (Organisation for Economic Co-operation and Development [OECD], 2015a). It also determines the outcome of an individual's school and work careers (Faix \& Laier, 1996; Kiper \& Mischke, 2008; Seligman, Ernst, Gillham, \& Linkins, 2009) as well as being the key to personal development (Crisand, 2002). Due to its high relevance in relation to work environments, it is seen as an important learning outcome within the field of vocational education and training, and it represents a growing area of interest in vocational research (Euler, 2016; Seeber \& Wittmann, 2017).

One important facet of vocational education is the fact that it targets the education of young people during the transition from school to work, particularly in the case of those young people who are disadvantaged for social or educational reasons and who experience difficulty in managing the transition (Ecarius \& Eulenbach, 2012). The potential to act in a socially competent fashion is important from two perspectives within this context. First, there is the issue of personal development, whereby young people have to complete developmental tasks in order to become responsible citizens. Second, social competence influences, to some degree at least, success in vocational professions and it is therefore a relevant learning goal in the field of vocational education and training. At first glance, the two perspectives seem to require different approaches with regards to how to construct social competence, namely either a more psychological or a more vocational educational approach. Yet, when considering young people and disadvantaged adults, it can be assumed that a more holistic approach is required, which involves aspects of both personal development and vocational professional guidance (in terms of vocational orientation). In recent years, many studies have attempted to develop concepts for the enhancement of social competence in a number of different contexts, for example, for higher education students (Euler \& Bauer-Klebl, 2009), for social care workers (Dietzen, Monnier, Srbeny, \& Tschöpe, 2015) and for school students (Yeates, 1989). In Germany, the "Fit for Life" programme (Jugert, Rehder, Notz, \& Petermann, 2010) includes a huge number of modules and methods that aim to target social competence, especially for young people with behavioural problems (i.e. at-risk youth). This approach is also used within the Werkschule Bremen ${ }^{1}$ educational course, which represents the research field in this study. The concept behind this specific educational course will now be briefly presented, which will lead to the research questions that inform this article.

The Werkschule is a three-year educational course localised within vocational education and training centres, and it is anchored in the education system of the federal state of Bremen, Germany. Students can complete either a regular (or so-called simple) school exam (after two years) or an expanded (after three years) Berufsbildungsreife in a learning environment that is two-thirds practically organised. The implementation of the Werkschule in Bremen aims to reduce the number of school-leavers without qualifications and can therefore be seen as a politically motivated innovation. The concept of the Werkschule is built on three main pillars:

\footnotetext{
${ }^{1}$ Henceforth, it will be referred to as the Werkschule.
} 
(1) psycho-social stabilisation of the students, which encompasses the characteristics of time, learning in teams and social-pedagogical support;

(2) vocational, project- and product-oriented learning, which also contains an element of seriousness; and

(3) further structural characteristics, for example, connection to the urban district, a probation period, and core school timetables, curricula and exams (Gessler \& Kühn, 2013).

Ideally, lessons are planned and conducted by teams of at least four people, including class teachers, subject teachers, masters (vocational professionals) and social pedagogues. The piloting of the Werkschule found the approach to be promising, although there is still the potential for optimisation in terms of social competence as a learning outcome. This became more important when teachers started to suggest that when students leave their old schools, they are no longer socially fit ('sie kommen sozial nicht mehr zurecht') (Gessler \& Kühn, 2013; Kühn, forthcoming). The students themselves highly valued the number of contrasts that they experienced between the Werkschule and their old school. The active creation of social learning environments, in contrast to already familiar situations and conditions, hence seems to be a productive starting point for concept development.

The present study is guided by the following research questions:

1. Which aspects of social competence are relevant learning issues within the Werkschule?

2. What do young people learn during an intervention developed specifically for the Werkschule?

3. Which factors are helpful and hindering in relation to the enhancement of social competence in the context of the Werkschule?

This study follows the generative design-based research approach (McKenny \& Reeves, 2012). It leads to an area-specific model of social competence (theoretical output) as well as to concrete content and factors (practical output) that have to be taken into account when attempting to enhance social competence in the context of the Werkschule. The remainder of this paper is organized as follows. Section two presents a short review of the actual state of the art regarding social competence, while the differences between a psychological, educational and vocational perspective are highlighted. Additionally, the preliminary work steps that are needed to understand the results are described. In section three, the methodological framework is described and the selection of the results is explained. After that, the results are presented. Following the theoretical and empirical findings, an area-specific model for the enhancement of social competence in the Werkschule is developed in section four. To help summarise the results, the term social literacy is proposed. Finally, in section five, the results are discussed and areas requiring further research are identified. 


\section{Social Competence: Identifying a Working Definition in a Broad Field}

Although there seems to be a general consensus regarding the meaning of social competence as an aspect of learning, there is presently far less agreement regarding an evidence-based model of this construct. The plurality of the approaches to defining and constructing social competence is the result of several factors. Practice requires functional approaches and 'what works' is adapted to the field, which is proven by practice itself. The scientific community instead focuses on theoretical constructs and, in fact, an increasing number of concepts with evidence-based impacts on practical settings. This section presents an overview of the main lines of discussion, exemplifies a number of approaches to enhance social competence and, finally, includes the definition of social competence utilised in the present study.

\subsection{An Overview of the Approaches to Social Competence}

The construct of social competence (Kiper \& Mischke, 2008; Rehder, Jugert, Notz, \& Petermann, 2001), social competences (Hinsch \& Pfingsten, 2007; Kanning, 2002) or social competency (Taylor, Liang, Tracy, Williams, \& Seigle, 2002) has given rise to controversial discourse. In general terms, (1) psychological, (2) educational scientific and (3) vocational educational definitions of social competence can be found.

\section{Theoretical Perspectives}

The psychological view differs in two key respects, since social competence can firstly be seen as a result of the successful development of one's personality (Oerter \& Dreher, 2008). The psychological manifestation of mental characteristics secondly represents the main perspective of psychological research in terms of psychometrics. An important field in this regard concerns the measurement of those characteristic values (e.g. Kanning, 2002). Social competencies in this context can therefore be seen as social skills, that is, the observable part of a psychical representation. Social competence here refers, naturally, to action in general social contexts (Seeber \& Wittmann, 2017). The relation between action and behaviour (not only) in psychological constructs remains unclear (Neubert, 2009). The separation between the psychical representation disposition and its realisation performance has also been adopted by the community of educational sciences, especially in the field of education standards (Klieme \& Hartig, 2007). The concept of competence (Weinert, 2001) defines competence itself as 'in all individuals available or learnable cognitive capabilities and skills to solve specific problems, as well as the related motivational, volitional and social willingness and skills to be able to successfully and responsibly use those solutions in various situations' (Weinert, 2001, p. 27-28). From this perspective, the focus is on the learnability of competence aspects, mostly in the fields of social and cultural learning, as well as lifelong learning (Gudjons, 2008; Straka \& Macke, 2009). Developmental challenges are not neglected, but rather enriched by the controlled growth of knowledge and capabilities in the different contexts of formal education, for example, kindergartens and schools. Due to this perspective, 
the related research focuses on the development and impact of teaching and learning environments under complex contextual conditions. The perspective of educational science considers the situational aspect of competence to be important to the theoretical model of social competence, which is reflected in the vocational education and training in Germany.

Over the last two decades, the German vocational education and training (VET) system has shifted towards a competence-orientation in both class and exams. Bader and Müller (2002) developed a basic concept of action competence and social competence, which represents one part of that orientation, in addition to professional and methodical expertise, as well as self-competence. All these components are understood as interacting facets of the construct of action competence. The (dual) VET system in Germany strongly refers to this concept due to its status as a key educational and political standard (Kultusministerkonferenz [KMK], 1996, 2007, 2011).

Social competence appears to be related to additional constructs, for example, intelligence, competence and skills. Monnier (2015) suggested a clarification of the relations between the named constructs through a 'proposed clean-up' (p. 70-71). The model she developed links different modes of action regulation (intellectual, knowledge-based and routine level) to fluid and crystallised intelligence as well as skills (Monnier, 2015, p. 70). Moreover, Monnier (2015) discussed the relation between the social and emotional aspects of the competence debate. She found that emotions play a major role in many aspects of social intelligence, competence and skills, although it is difficult, if not impossible, to separate the emotional aspects from social intelligence, competence and skills (Monnier, 2015, p. 70). Yet, in terms of social situations, intelligence, competence and skills can be separated. These results demonstrate that the role of emotion in approaches to enhance social competence must be taken into account.

As the Werkschule addresses those who have dropped out of school, many of the targeted young people have experienced problematic or frustrating school careers. They have often lost the fun in learning, which can culminate in school absenteeism. Additionally, they may have behavioural problems, so that they perhaps just do not know how to successfully act or express themselves socially. The Werkschule itself provides a practical approach for such students, since it is assumed that they might learn better in a more practical rather than theoretical context. The evaluation of the pilot scheme indicates promising results (Gessler \& Kühn, 2013). It appears necessary to take all three lines of discussion into account when attempting to enhance social competence in the special context of the Werkschule. Social competence is here defined as

the cognitive skills and abilities available to individuals or learnable through them in order to solve problems in social situations as well as the related motivational, emotional and volitional willingness to successfully and responsibly use the problem solutions in standardized and value-oriented situations (Kühn, forthcoming). 
General Aspects of Enhancing Social Competence in School Contexts

The concept of enhancing social competence is part of a variety of social, educational and psychological fields, and it therefore cannot be presented to its full extent. Instead, an overview is provided regarding the school-related approaches, which represents the specific focus of the paper. Basically, the approaches can be differentiated into behaviourand relation-oriented approaches (Achtenhagen, 2008; Jerusalem \& Klein-Heling, 2002). The concepts to enhance social competence mostly focus on a selection of social competence characteristics, for example, prosociality (Kienbaum, 2016), empathy and moral awareness (Baumgartner \& Alsaker, 2016), and assertiveness and perspective taking (Perren, Argentino-Groeben, Stadelmann, \& Klitzing, 2016). Further, there seem to be two important issues regarding the positive long-term effect of the concepts related to enhancement. First, not only a single group (i.e. a class) is involved, but rather the whole school, if possible (Strohmeier \& Spiel, 2016). Second, an intervention requires a clear and repeating agenda, as well as intensity (Merrill, Smith, Cumming, \& Daunic, 2016). The actual forms of intervention are the analysis and modification of behaviour, counselling and therapy, social skills training, peer-mediation, cognitive interventions and self-management, as well as multiple interventions (Jerusalem \& Klein-Heling, 2002).

Further research regarding social competence shows the close connection between an individual's ability to succeed in social interactions and his/her cognitive performance (e.g. Seligman et al., 2009), which is particularly relevant in relation to school education, especially for drop-outs. Bringing students back to school requires making school fun again. As Ecarius, Höl and Berg (2012) have shown, a different experience in a new school can prove helpful in overcoming and revising prior bad experiences. Additional promising approaches include positive education (Seligman et al., 2009), experiencebased education (Gudjons, 2008; Möbus, 2013) and the creation of a positive learning climate (Brüning \& Saum, 2009), which naturally involves both students and teachers. The following section briefly describes the main issues concerning the Werkschule and then presents a concept that was developed based on its specific conditions.

\subsection{A Didactical Working Model for Enhancement of Social Competence}

Based on the theoretical background, an initial model to enhance social competence in the context of the Werkschule was developed, which is presented in Figure 1. Working through the model, it is first assumed that social competence as a learning outcome needs to be elaborated by the teaching staff. Each individual situation that requires action has specific conditions at its heart (i.e. a conflict: Who was/is involved? Where did the action take place? How did the problem begin? How complex was/is the situation? What are the requirements and given targets?). Teachers represent requirements in terms of their (vocational) profession and they have to make these aspects transparent to the students in order to make a holistic understanding of the situation possible. The situational aspects have to be understood so as to provide helpful information to the actor(s). Therefore, the attention of the students has to be given and the environmental stimuli changed to information in order to become relevant to the students (Straka \& 
Macke, 2005). As Aarkrog and Wahlgren (2017, p. 56) have noted, the elaboration of competence as a learning goal must be both defined in relation to the context and not too detailed. Moreover, based on the results of their study, they concluded that thinking about assessment instruments leads to the highlighting of social competence in practical learning environments (Aarkrog \& Wahlgren, 2017, p. 63). This produces awareness regarding the design of learning environments as well as the role of social competence within those environments. Hence, an adequate definition of a learning task is essential.

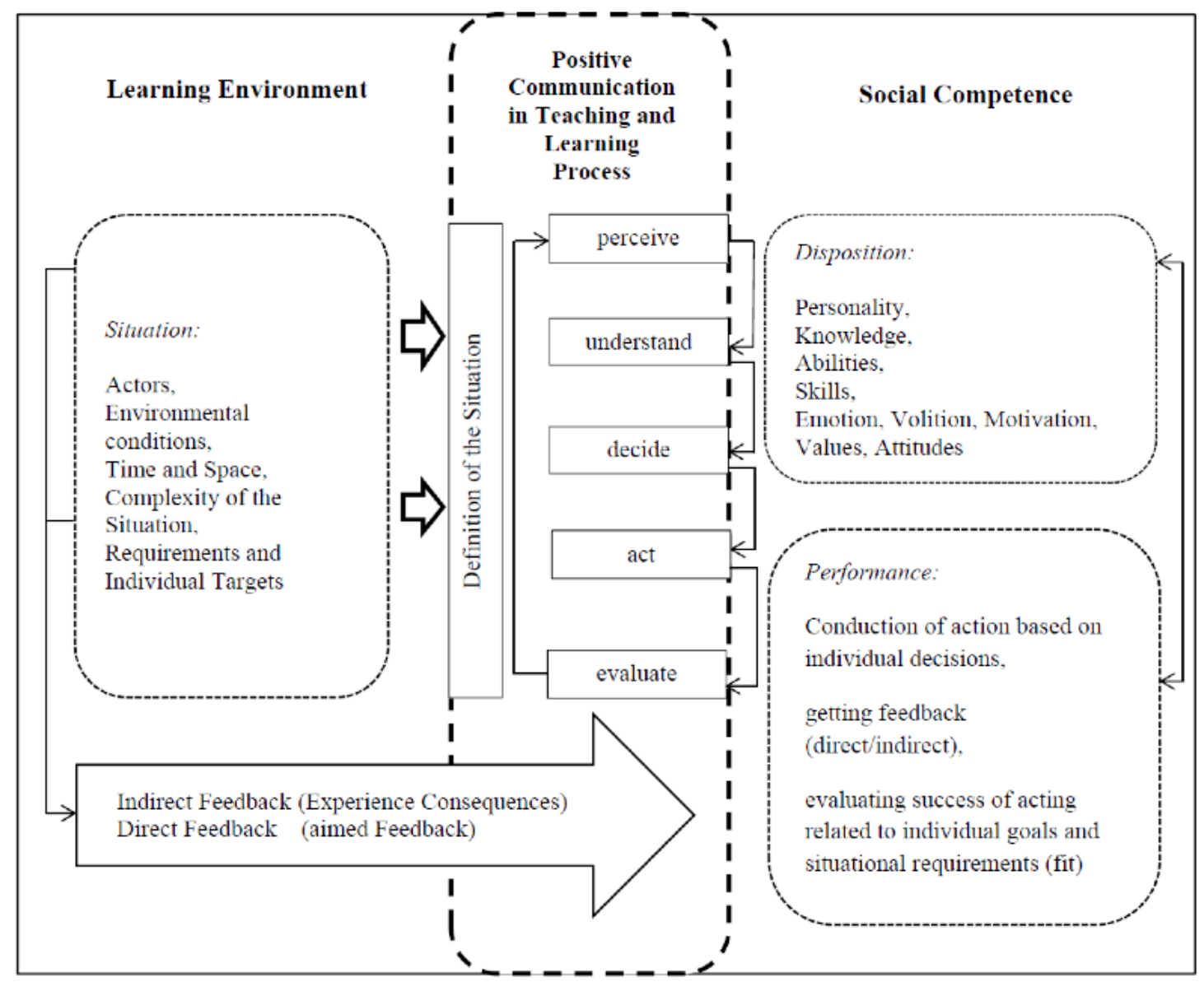

Figure 1: Working model of a didactical framework to enhance social competence in the Werkschule. (Source: author's own illustration, following Dörner, 2011; Euler \& Bauer-Klebl, 2009; Jugert et al., 2010; Neubert, 2009; Seligman et al., 2009; Straka \& Macke, 2005).

The model of a complete action with its conceptual proximity to the cognitive (here: social) information processing model serves as a fitting illustration of the learning process, and it includes the following steps: perceive, understand, decide, act and evaluate. These iterative steps are closely connected to the aspects of social competence, either 
the individual disposition or the concrete performance. This process has to be attended by those who take over teaching tasks. According to the concept of positive education, the language used is resource-oriented and respectful. There are (at least) two feasible ways to evaluate actions in terms of their success: students could learn by receiving feedback directly through experiencing the consequences that accompany an action, or those involved in the learning task could provide direct feedback. Both variants need to be reflected if they are to become experience-based knowledge and, relatedly, enhance social competence.

In order to develop learning tasks, the degree of complexity of a given social situation must be taken into account. Minimal complexity makes it easier to adapt new knowledge and action processes, while too high a degree of complexity might prove frustrating and cause a refusal of the task.

\section{Design-Based Research as a Methodological Framework}

The research questions that inform this study target the usability and impact of an intervention that will be developed. This leads to a research design that highlights development-oriented practice research. The design-based research (McKenny \& Reeves, 2012) approach appears promising, since it leads to practical solutions on the one hand and scientific findings on the other (Cobb, Confrey, diSessa, Lehrer, \& Schauble, 2003; Euler, 2014).

Design-based studies follow a phase-based structure. In phase 1, the problem is defined, while phase 2 foresees the development of a solution to the practice problem and phase 3 concerns the validation of the solution's implementation. One core aspect of the design-based research approach is the iterative optimisation and adaptation of an intervention or concept. Each so-called micro-cycle involves the following work steps: design, implementation, analysis and re-design.

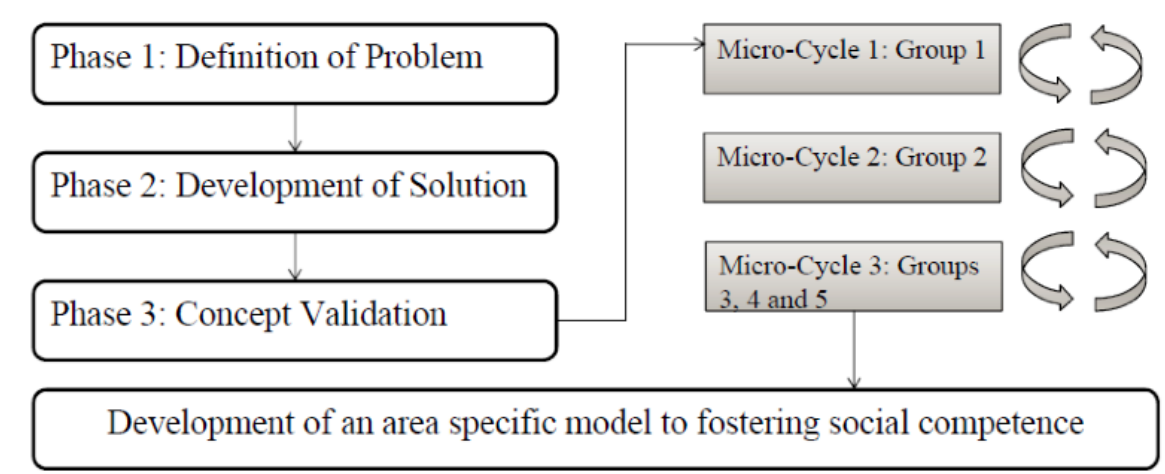

Figure 2: Design-based research design for the study (Source: author's own presentation, following McKenny \& Reeves, 2012). 


\subsection{Design Principles and Quality Criteria}

The design-oriented research approaches are still undergoing the formation process. Nevertheless, it seems certain that these types of research design need to realise some special characteristics (McKenny \& Reeves, 2012), namely principles (Euler, 2014). The designbased research approaches are: iterative, orientated in interventions, collaborative, oriented in use (ability), theory-based and integrative. They deliver area-specific theories (Euler, 2014; Reinmann, 2010), design frameworks or design methodologies (Reinmann, 2010).

This study targets the following principles. The iteration is achieved via the implementation of three micro-cycles, which serve as optimisation cycles for the intervention as well as the research context of the impact on learning. An intervention was developed and tested. Collaboration during the research process was realised by means of exchanges with the involved teaching staff, the second observer (see description of micro-cycles two and three) and an external expert. Moreover, the students actively took part in feedback sessions and informal reviews during the implementation process. The use of the research approach and the results were determined by the interest of the involved school actors in the intervention, including a didactical structure (learning goals, fostering environment, methods) and examples of implementation (best practice). The theoretical basis is formed by the theoretical didactical working model (cf. section 2.2 ), which combines all the relevant theoretical findings concerning to enhancement of social competence in the Werkschule. The research methods were chosen according to the needs of each individual phase and micro-cycle in order to comply with the integrative aspect. For all the utilised research methods, whether qualitative or quantitative, the related quality criteria were maintained.

The design-based research does not only explore and test what is, but also what could be (Schwartz, Chang, \& Martin, 2005). It represents a change requirement and, therefore, has a significant influence on practice, which is the subject and object of this research.

\subsection{Presentation of the Study}

As mentioned above, this study aims to assess the design and impact of an intervention intended to enhance social competence in the Werkschule. The design and testing are both related to the system of the design-based research. This means that the implementation of the research occurs in phases and micro-cycles. Each phase and each micro-cycle has its own sample and research methods, which are customised to the scientific requirements of the development, namely the research step. First, the general structure is presented, although only micro-cycle three is highlighted in terms of the findings.

To concretise the research problem (phase one), two things were necessary. First, the curricular framework and learning goals regarding social competence had to be identified, which was achieved through a literature review. Second, the actual practice had to be captured, including the important topics, learning goals and didactical challenges. Addi- 
tionally, the organisational frame of the intervention to be developed was determined. To realise this step, a group interview was conducted with four teaching teams, which were represented by seven teachers, four social pedagogues and two masters. The necessary conditions for taking part in the interview were (1) at least two team members had to take part, (2) the teaching team would start with a $9^{\text {th }}$ grade class the following school year (first year of the Werkschule) and (3) voluntary attendance. Information regarding the project was circulated and participants were acquired during a board meeting of class teachers. In relation to the responses, no further selections were necessary. The core result of phase one was clarity regarding the conditions of the intervention as well as the necessary content.

In phase two, the intervention itself was designed. Therefore, the results from phase one were situated in relation to the relevant theoretical approaches by interlinking the phases one and two. The first draft of the intervention, the so-called prototype, formed the basis for the concept validation (phase three).

Phase three can be separated into three steps or micro-cycles (Figure 2). Each had a special focus on the optimisation of the prototype in terms of its didactical structure and methodology as well as on the learning aspect related to the participants. In total, five classes of students from four different Werkschulen took part in the study (Table 1). The classes were related to the participants in phase one in order to create a link between the problem definition, development of the solution and transfer of the intervention into practice. The teachers were all informed about what would happen in class, while communication between the researchers and the teaching team was assured during the implementation and adaption phases.

Table 1: Samples involved in micro-cycles 1 to 3 (Source: author's own research)

\begin{tabular}{ccccccc}
\hline $\begin{array}{c}\text { Micro- } \\
\text { cycle }\end{array}$ & GR & M & F & Age & Total & Field of Profession \\
\hline 1 & 1 & 5 & 7 & $14-16$ & 12 & Food Preparation and Elderly Care \\
2 & 2 & 0 & 14 & $14-16$ & 14 & Food Preparation and Personal Services \\
3 & 3 & 11 & 1 & $14-16$ & 12 & Metal Construction \\
& 4 & 5 & 9 & $14-17$ & 14 & Food Preparation and Elderly Care \\
& 5 & 7 & 2 & $15-17$ & 9 & Colour and Wood Technics \\
\hline
\end{tabular}

The groups had to comply with the following conditions: (1) the participating class was a $9^{\text {th }}$ grade class, which means the first year of attending the Werkschule; (2) the entire teaching team (or at least two people from the team) took part in the group interview; (3) the responsibility for the intervention was left to the researcher; and (4) the teachers' decision to participate was voluntary. To satisfy these conditions, it was necessary to reach maximum comparability in heterogeneous contexts. The first micro-cycle was 
based on group $1(\mathrm{n}=12)$, micro-cycle two on group $2(\mathrm{n}=14)$, while the third microcycle involved groups $3(\mathrm{n}=12), 4(\mathrm{n}=14)$ and $5(\mathrm{n}=9)$. This distribution is explained in the following paragraph.

In micro-cycle one, the fit of the different methods related to the target group was investigated. Reflective discussions conducted with the teacher and an external expert in extracurricular youth education validated the process of implementation within group 1 . Further, the observations were analysed and feedback from the students was gathered. At the end of micro-cycle one, the first optimisation of the prototype was made (redesign). Relevant changes affected the logical structure of the concept, which refers to the sequence of content and the time structure. Furthermore, the type of methods used within the intervention tended towards a clearly practical orientation rather than theoretical methods, for example, discussion rounds or concept cards.

Micro-cycle two focused on pretesting the research methods for micro-cycle three while testing the optimised version of the intervention (prototype 2). Again, the students' feedback was used to make changes to the didactical methodological structure. The other aim of micro-cycle two was to collect data regarding what was learned as well as to gather information about any necessary adaptions for micro-cycle three. Therefore, three means of data collection were applied. In order to include several perspectives on the optimisation process, two types of data were collected. The qualitative feedback gathered from the students delivered not only information about what they liked and disliked and why, but also what they thought they had learned. This feedback was noted and compared to the quantitative data regarding their participation in the intervention. Two observers (the researcher and another person with an educational background) evaluated the students' participation in the intervention. The students were also asked to answer questions regarding their actual state of interest, motivation and sense of well-being (scales adapted from Wolf, 2003) at fixed points during the process. This information was used to obtain an impression of the relation between emotional experience, learning and participation. Additionally, a scale intended to capture the students' actual expression of social competence was implemented (Inventar Soziale Kompetenzen [ISK]; Kanning, 2009).

Moreover, a final round of quantitative questioning was undertaken regarding motivation (Kramer, Prenzel, \& Drechsel, 2000), self-efficacy (Jerusalem, Drössler, Kleine, Klein-Heling, Mittag, \& Röder, 2009) and selected items from the self-determination scales (Deci \& Ryan, 1993; Kramer, Prenzel, \& Drechsel, 2000). The strongly explorative approach of micro-cycle two found that, although the items were simplified linguistically, the students had problems answering the questions. The interim inquiry (self-reported data regarding emotional experience etc.) revealed no major problems. Using a factor analysis and a reliability analysis (non-parametric testing because of the small number of participants), the questionnaires could be reduced and sharpened.

The intervention was implemented in three classes during micro-cycle three. As the intervention was conducted by the researcher herself, it was not possible to run parallel interventions, although each implementation took place within a time span of eight weeks to ensure that the students were all reached in a comparable state. The time schedule was the same for all the schools; only the individual starting and ending time differed. The 
intervention lasted five days and contained five different topics and their related worktasks regarding social competence. The tasks can mainly be differentiated by either a more theoretical (i.e. group discussions) or a more practical (i.e. group-dynamic games) approach. As described above, the following data were collected: participation of the students (observation using a quantitative surveillance sheet by two observers), experience of the process (quantitative self-reports by the students at three fixed points per day) and qualitative feedback from the students regarding individual days. In order to assess the pre- and post-effect of the intervention, daily topic-related concept maps were added and analysed in both qualitative and quantitative ways. Each run was concluded by a digital final inquiry (evaluation software).

To make a determination of the context-relation of the results possible, school-specific issues and observations were noted and discussed by both observers so as to clarify the role of each identified factor and value its anticipated influence on the enhance of social competence. The results are presented in the following section.

\section{Core Results of the Iterative Testing}

Before introducing the findings, it is useful to restate the leading research questions. What did the students learn? Which contextual factors seem to be enhancing/hindering social competence? Is a "one-size-fits-al" solution for the individual locations of the Werkschule feasible? The results are first presented in relation to the methodological approach (section 4.1). After that, an overall discussion follows. In section 4.2, the results are consolidated into an area-specific model for enhancing social competence in the Werkschule.

\subsection{Selected Results of the Concept Validation}

The results relate to a comparison between the three groups. Two of them had similar conditions, while the third group served as a reference group. The comparison was not based on taking part or not taking part in the intervention, but instead concerned the age and class level of the students (groups 3 and $4=9^{\text {th }}$ grade, group $5=10^{\text {th }}$ grade). Groups 3 and 4 only knew each other for a few weeks, while group 5 was together as a class for over a year, with all the associated and occasionally problematic group dynamics, role allocations and conflicts.

\section{Observation of the Students' Participation}

The students' participation was valued on bipolar scales regarding the dimensions of oral expression (passiveactive, on-topicoff-topic), listening, concentration and respectful handling of others. The reliability of the scales (Cronbach's $\alpha$ ) ranged from satisfactory ( $\alpha .=753$, lowest value) to very good $(\alpha=.916$, highest value). The overall score of all three groups of participating students in micro-cycle three was compared. The observation data included two collection points per day: one related to a more theoretical setting and the other to a more practical setting. In order to identify which settings lead to more active participation, the data concerning both types of methodological settings 
were compared. Due to the small number of groups as well as to relate the item-pairs, Kendall's tau-b $(\tau-\mathrm{b})$ was computed. This value is resistant to statistical outliers and is therefore a suitable measure (Caspar \& Wirtz, 2007). There were two findings regarding this issue of analysis. First, the item-pairs correlated significantly, especially for the more practical settings. The more theoretical settings showed significance for only half the item-pairs. This leads to the assumption that participation can be better observed in more practical settings. This is of great importance when it comes to assessment in school contexts. Social competence must be assessed where it is shown and not where it is discussed, since practical settings provide a context that leads to the more accurate assessment of existing competence than theoretical settings do. Second, the participation itself appeared to be at a very high level (ranging from " $3=$ rather good" to " $4=$ very good"). It was interesting to note that the reference group presented the highest variations within the observed items. The standard deviation decreased for the more practical settings and the curve progressions of the three groups drew near. This finding suggests that more practical settings represent a better arena for active participation and, relatedly, better learning conditions.

\section{Students' Experience of the Process}

The students' cognitive and emotional experiences were collected by means of quantitative, self-reported and process-related questionnaires. The items targeted well-being, feeling of being taken seriously, being interested, understanding of the actual topics/tasks and feeing glad to take part. These five items were answered at the start, in the middle and at the end of each working day.

The students' experience of the working process was on a level similar to their participation. The daily averages concerning experiencing the intervention were higher than $\mathrm{M}=3.00$ on three days ( $\mathrm{N}=$ from 24 to $28 ; 3=$ "rather good"). On days three and four, the average was a little lower, with a minimum value of $\mathrm{M}=2.97 \quad(\mathrm{SD}=.029, \mathrm{~N}=24)$. Between groups 3 and 4 there were no significant differences, while the reference group differed on nearly all points. The values regarding the experience of the intervention as well as the related participation vary throughout the whole process, much more so in fact than for the other groups. However, the reference group was the group that exhibited the most changes in participants, positive or negative work climate and time structure (beyond the intervention). Taken together, the positive experiences correlated with practical settings, while the results for the more theoretical settings had a higher distribution. The overall experience was mostly positive, which indicates, together with the high values in terms of participation, a productive learning environment.

\section{Effects on Learning}

The intervention's effect on learning was examined in two principal ways. First, the students completed a mind map regarding the daily topic at the beginning of each day. At the end of the day, they were allowed to write some additional words or sentences on their mind map (in a different colour). The mind maps were analysed qualitatively (reference to which topic?) and quantitatively (how many more, if qualitatively relevant?). Second, the students self-reported their subjective perceived expression of social competence 
at the start and end of each day. The items were taken from the ISK and the data collection was conducted in a media-based fashion (evaluation software). The utilised subscale was social orientation, which was selected due to its high correlation with the topics and targets that the teachers reported to be necessary in the group interview (phase two). The reliability was satisfactory (prosociality: $\alpha=.735$, six items; listening: $\alpha=.754$, eight items; plurality of values: $\alpha=.701$, ten items) and good (willingness to compromise: $\alpha=.771$, eight items) to very good (change of perspective: $\alpha=.918,13$ items). The main finding regarding the first part was that the students mostly noted topic-related words or sentences.

Table 2: Qualitative analysis of the students' mind maps (Source: author's own research)

\begin{tabular}{lcccccl}
\hline Dimension & PRE & \multicolumn{2}{l}{ POST } & \multicolumn{2}{l}{ GES } \\
& N & $\mathbf{\%}$ & N & $\mathbf{\%}$ & N & Words total (\%) \\
\hline Prosociality & 80 & 70.2 & 30 & 26.3 & 114 & 96.5 \\
Change of perspective & 26 & 35.6 & 22 & 30.1 & 73 & 65.8 \\
Listening & 52 & 57.1 & 25 & 27.5 & 91 & 84.6 \\
Willingness to compromise & 6 & 6.5 & 13 & 14.1 & 92 & 20.6 \\
Plurality of values & 10 & 12.3 & 55 & 67.9 & 81 & 80.2 \\
\hline
\end{tabular}

As shown in Table 2, on four out of five days, the students referred to the daily topic. Each day, words were added regarding what was seen as an effect on learning. It is noteworthy that for prosociality and listening, the students mentioned more words at the beginning, while the number of added words decreases to up to half of the prenumber. This finding is different for the three other dimensions of social orientation. It is particularly interesting to note the dimensions of willingness to compromise (only a few words, but later more than before) and the plurality of values (four times as many words as before). This aspect will be discussed further following the presentation of the quantitative results derived from the self-reports. One further important finding was that those students who made additional notes had already written something at the beginning of the day ( $\mathrm{N}=16$, biggest group). However, only three students who presented learning indicators had no prior knowledge in that regard. There was also a group of students who refused to take part in the data collection $(\mathrm{N}=6)$ for a number of reasons.

The quantitative self-reports concerning social orientation were based on the same structure for each day. The questions regarding the single dimensions were formulated as 'I know what it means...' ', 'I am able to do...' and 'I consider it important that...' in order to imply all the facets of competence. The analysis showed similar ratings for groups 3 and 4 . For each day, the students experienced a little growth in their social competence, whereby the pre- and post-differences were mostly not significant 
(Wilcoxon-Test). The exceptions to this were the dimensions of prosociality and the plurality of values, where the reported learning effect became significant.

The above findings lead to the assumption that some groups found some days that offered a positive learning environment (participation and positive experience) to be accompanied by small, but existing learning effects. Special observations were made for the intervention days one (prosociality) and five (plurality of values). When compared to the other days, differences are apparent. On the first day, the students started the intervention in a motivated, but undifferentiated fashion. The effects on learning became more differentiated during the following days. The result seen for the last day was based on the free and controversial discussion of the heterogeneity of people and individual values. After that, the students were asked to present what they had learned over the course of the week in a presentation of whatever form they liked. On this day, several obviously fostering factors came together. That is, the students were personally affected, adequate room to be creative was provided and the topic was easy to understand for everyone, for example, when compared to the willingness to compromise. Here, many students experienced greater difficulty in developing solutions to the given problems and even explaining what a compromise actually is. In conclusion, an evaluation of the didactical-methodological concept and the identified fostering and hindering factors is briefly presented in order to outline the context.

\section{Evaluation of the Didactical Concept and Identification of the Fostering Factors}

The didactical and methodological concept was evaluated using the media-based selfreports of the students. The requested dimensions were: (1) topic-related interest, (2) didactic-methodologic conception, (3) competence support (extracted from the selfdetermination scales following Deci and Ryan [1993] and Prenzel and Drechler [1996]) and (4) context conditions. The reliability of the scales ranged from good to very good. The focus is on which learning conditions were seen as enhancing or hindering social competence. The intervention was valued as rather good. The majority of students preferred the more practical settings and evaluated them as the settings in which they learned the most.

Of additional importance were the clarity of instructions and the comprehensibility of explanations. The two main findings were that the students missed a vocational orientation (subjective relevance of content) in the rather general frame of the content. Further important findings were that the conduct of an external person (independence of person) was experienced as motivating (fun) as well as providing something different from conventional teaching (experience of contrast). The access to social experiences and social integration was evaluated as rather good in all the groups. The perceived difficulty and time schedule seemed to fit with the students' abilities. 
Table 3: Fostering and hindering contextual conditions based on the process observations

(Source: author's own research)

\section{Fostering Conditions $\quad$ Hindering Conditions}

\begin{tabular}{|c|c|c|}
\hline \multirow[t]{5}{*}{ Teachers } & Detailed planning & Lone fighter mentality \\
\hline & Presence in the intervention & Rigid insistence on compliance \\
\hline & Interest in the intervention & with rules without (critical) discus- \\
\hline & Appreciation of students & \\
\hline & Active design of relationships & \\
\hline \multirow[t]{4}{*}{ Students } & Willingness to actively participate & Psychological problems \\
\hline & Continuous presence & \\
\hline & Appreciation of teachers & \\
\hline & Appreciation of peers & \\
\hline \multirow[t]{6}{*}{ Teaching } & Long-term design of social com- & Lack of structure or continuity \\
\hline & petence learning environments and & Predominant forms of problematic \\
\hline & $\begin{array}{l}\text { concepts } \\
\text { Inteoration of teachino and distur- }\end{array}$ & \\
\hline & $\begin{array}{l}\text { Integration or teacning and distur- } \\
\text { bances }\end{array}$ & \\
\hline & Transparent problem-solving & \\
\hline & Respectful communication & \\
\hline \multirow[t]{6}{*}{ Team } & Perception of the team as a unit & Lack of identification with the \\
\hline & Perception of enhancing social & team \\
\hline & competence as a common task & \\
\hline & Common teaching objectives & \\
\hline & Resource-oriented perception of & \\
\hline & & \\
\hline \multirow{4}{*}{$\begin{array}{l}\text { Organi- } \\
\text { sation }\end{array}$} & Support by school leadership & Lack of time resources needed to \\
\hline & Provision of rooms & explicitly enhance social compe- \\
\hline & Provision of technical equipment & tence \\
\hline & & $\begin{array}{l}\text { Lack of concepts needed to en- } \\
\text { hance social competence }\end{array}$ \\
\hline
\end{tabular}

Although the concept was beneficial to all the groups from micro-cycle three, there were differences seen with regards to the school environment. The learning environment related to the participating groups was observed throughout the duration of the intervention, but also during the initial introductory meeting. The intervention days with the active participation of the students were reflected by the following variables: (1) teachers, (2) students, (3) teaching, (4) team and (5) organisation. Additionally, all the experiences engaged in with the participating teaching teams were reflected, which 
involved the entire research process. The observations were listed and, after reflecting on well-run and problematic situations during the intervention days, condensed into fostering and hindering contextual conditions (Table 3).

The three groups differed not only in relation to the implementation process and the results, but also in terms of the environmental conditions. The two targeted groups demonstrated better conditions in which to, first, run the intervention and, second, lay the foundation for the sustainable implementation of the enhancement approach. In contrast, the reference group combined many hindering factors, especially with regards to the teacher-student relation, which appeared to be an important factor in terms of enhancing social competence.

The results are limited to the method, since the observations were performed while conducting the intervention. A specific focus on observation and less on attendance in the field could have led to more resilient results.

\subsection{An Integrated Model for the Enhancement of Social Competence in the Werkschule}

Enhancing social competence for disadvantaged young people requires didactic specifics that could be identified and elaborated due the iterative structure of the present study. The findings were brought together in an area-specific model to enhance social competence in the Werkschule, which is presented in Figure 3. The content required a clear relation to the work or living environment. Determining what has to be learned for which reason can provide students with a purpose and increase their motivation, which forms the basis for the emergence of willingness to participate. Work- and learningrelated tasks have to be oriented towards the abilities of the students in order to balance support and regulation. Therefore, an adequate degree of complexity is necessary. Furthermore, everything that clearly differs from the familiar aspects of school seems to be motivating, since it does not directly affect negative school experiences. The targeted production of the experience of contrast can be achieved through the irritation of the students by unexpected actions or remarkable changes in the learning environment. Additionally important is the change in the students' perspectives on social competence. If social competence is seen through the narrow scope of positive behaviour during class, resistance might appear, since this aspect often necessitates a rigid following of rules without an understanding of the subjective triggers.

Moreover, students like to discuss their opinions and moral concepts. In this study, they appeared to like participating in discussions about tangential topics of individual importance. Their teachers' and their peers' opinions serve as necessary projections, surfaces and anchors for moral and value orientation, which is itself fundamental for socially responsible actions. Discursivity, therefore, is seen as an important aspect of such fostering approaches. Activity facilitates access to learning and positively influences the motivation to learn. Group-dynamic tasks and exercises related to communication and cooperation also showed a positive effect. Both discursivity and activity are connected through a reciprocal relationship, which accounts for the basic model of social informa- 
tion processing. The planning, implementation and reflection of actions belong together as learning aspects, if the ability to act is targeted.

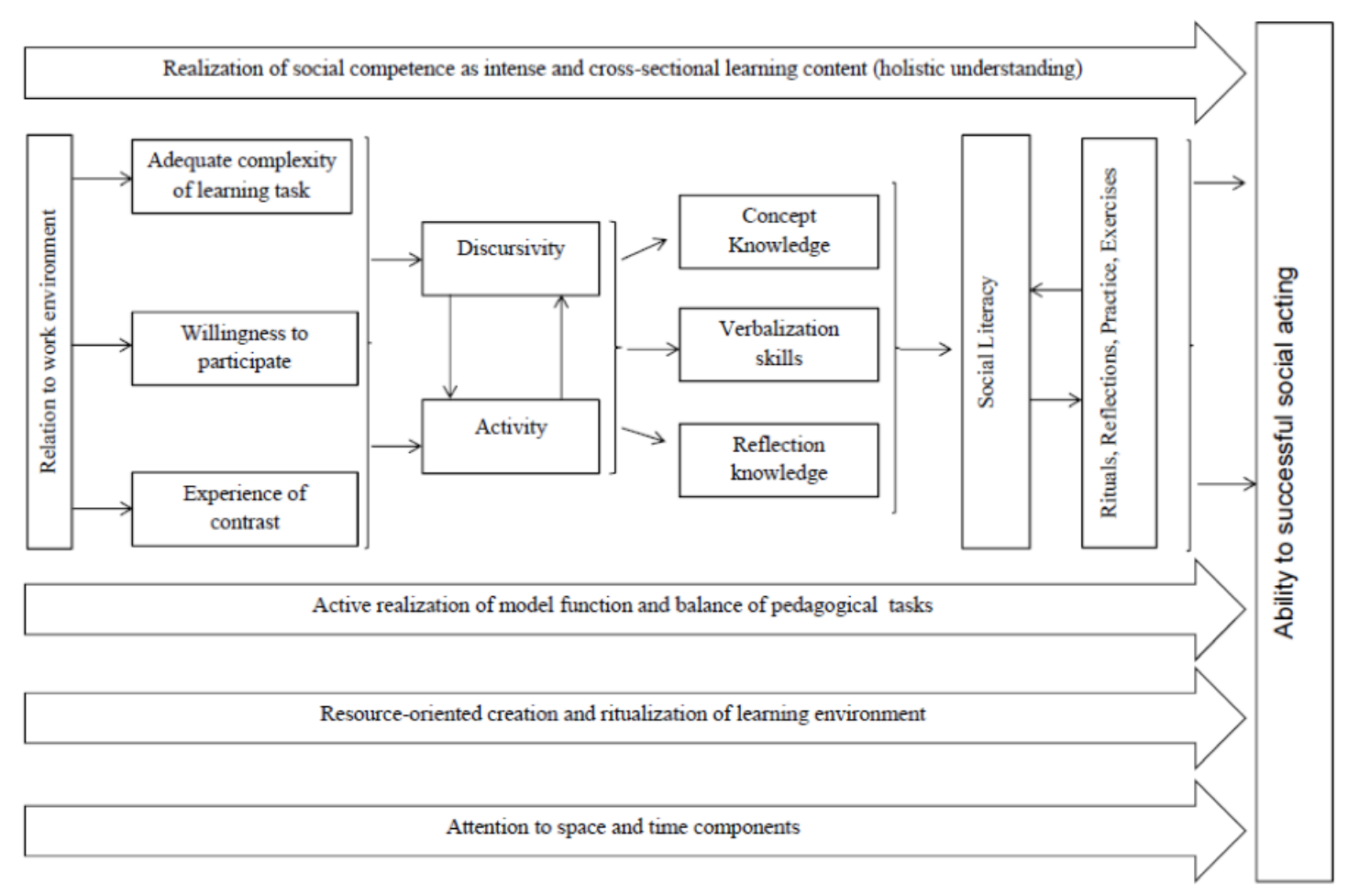

Figure 3: Area-specific model to enhance social competence in the Werkschule (Source: author's own research).

The realisation of work and learning tasks, supplemented by reflexive processes and topic-related discussions, leads to factual knowledge (knowing and understanding various aspects of the learning content), the ability to verbalise those aspects (description and expression of mental states and the connections between single aspects of factors that work together in social action contexts) as well as reflection knowledge. The findings showed that the young people had only rather poor knowledge and ability with regards to initiating productive reflection processes. Due to this, reflection is seen as an inherent facet of learning.

Interestingly, the intervention reached students with and without prior documented knowledge. In this regard, the concept succeeded in the enhancement of the language ability related to social competence. This refers to the ability of the young people to receive stimuli from a social situation and transform them into information (Straka \& Macke, 2005). The young people are able to consider adequate actions, not before they understood the Situation's requirements (signals resp. stimuli). All the learning processes lead to increased ability regarding social action, that is, social competence. The important supporting contextual factors include time (to develop stable changes in per- 
sonality and individual possibilities for action), intensive work and learning units as well as the interdisciplinary integration of social competence in class (social competence as an intense and cross-sectional learning content), a positively designed learning environment and, finally, the teachers' model functions as both a chance and a challenge in terms of issues of enhancement.

\section{Conclusions and Suggestions for Further Research}

The present study has made a number of key contributions to the literature. Following the existing requirements of design-based research, it is clear that each research project must lead to a practical output. This is necessary because these types of research designs arise from practical problems and target the development of applicable solutions. Within this study, a didactic-methodologic concept was developed and tested. The final and revised version includes a theoretical foundation, learning goals, recommendations regarding the didactical structure and the choice of methods, and empirically based knowledge concerning how to implement the intervention and related factors that may lead to sustainable change. Two further steps seem to be important. First, the results of the study have to be published to teachers. Second, the teaching staff might require further education on the team-based approach.

In terms of avenues for further research, the findings of this study lead to a couple of questions that are not only important for the Werkschule, but also for all educational contexts: How is the social competence of teaching staff constructed? Which aspects of social competence do teachers require and how strong is their need for further education? Moreover, the construct of social literacy needs to be theoretically developed and proven as a possible pillar of basic education, in addition to literacy and numeracy. The necessity of the ability to express inner experiences in order to reach emotional regulation is widely accepted (Hascher, 2005; Schonert-Reichl \& Lawlor, 2010). It has also been proven that successful emotional regulation effects learning motivation in a positive way (Pekrun \& Schiefele, 1996). Emotion itself is discussed as being related to the construct of social intelligence (Kang, Day, \& Meara, 2006), which effects the cognitive aspect of emotional and social issues. Due to the close intrapersonal and interpersonal connection between the emotional and social aspects, it is clear that knowledge and language ability in the field of social interactions are important conditions for perceiving, understanding, planning and evaluating social actions. The ability to express one's mental state and situational targets as well as to react adequately linguistically represents an important aspect of social problem solving, which happens to be a core element of the social competence discourse (Merrill et al., 2005). In addition to the linguistic issues, there is the question of cultural aspects as represented in specific understandings of social competence. The adequacy of an action must be seen in the context of interculturality, which is becoming more and more important in the Werkschule and elsewhere. The discussion regarding whether or not situational requirements are legitimate (i.e. in work environments, families, peers, school contexts, etc.) is therefore of high relevance due to the fact of cultural diversity. 


\section{References}

Aarkrog, V., \& Wahlgren, B. (2017). Developing Schemas for Assessing Social Competence among Unskilled Young People. In: International Journal for Research in Vocational Eucation and Training (IJRVET), 4(1), 47-68. doi:10.13152/IJRVET.4.1.3

Bader, R., \& Müller, M. (2002). Leitziel der Berufsbildung: Handlungskompetenz. Anregungen zur Ausdifferenzierung des Begriffs. In: Die berufsbildende Schule 54 (6), $176-182$.

Brüning, L., \& Saum, T. (2017). Strategien zur Schüleraktivierung (5. überarbeitete Auflage). Erfolgreich unterrichten durch kooperatives Lernen: L. Brüning, T. Saum; Essen: Neue Deutsche Deutsche Schule Verlagsgesellschaft mbH.

Cobb, P., Confrey, J., diSessa, A., Lehrer, R., \& Schauble, L. (2003). Design Experiments in Educational Research. Theme issue: The Role of Design in Educational Research. In: Educational Researcher Vol. 32(1), 9-13.

Crisand, E. (2002): Soziale Kompetenz als persönlicher Erfolgsfaktor. Arbeitshefte Führungspsychologie, 41. Heidelberg: Sauer.

Deci, E. L., \& Ryan, R. M. (1993). Need satisfaction and the self-regulation of learning. In: Learning and Individual Differences Vol. 8 (Nr. 3), 165-183.

Dietzen, A., Monnier, M., Srbeny, C., \& Tschöpe, T. (2015). Soziale Kompetenz medizinischer Fachangestellter: Was genau ist das und wie kann man sie messen?! In: Berufs- und Wirtschaftspädagogik - Online Spezial 10 - Berufsbildungsforschung im Gesundheitsbereich. Retrieved from http://www.bwpat.de/spezial10/dietzen_etal_g esundheitsbereich-2015.pdf

Dörner, D. (2011). Die Logik des Misslingens. Strategisches Denken in komplexen Situationen. 10. Ed.; Reinbek near Hamburg: Rowohlt-Taschenbuch-Verlag.

Ecarius, J., \& Eulenbach, M. (2012). Jugend und Differenz: Aktuelle Debatten der Jugendforschung. Wiesbaden: Springer Verlag.

Ecarius, J., Höl, S. E., \& Berg, A. (2012). Peergroup Ressource oder biographische Gefährdung? In: J. Ecarius und M. Eulenbach (Ed.): Jugend und Differenz: Aktuelle Debatten der Jugendforschung (p. 161-181). Wiesbaden: Springer Verlag. Retrieved from http://link.springer.com/chapter/10.1007/978-3-531-92088-7_8

Euler, D. (2014). Design-Research - a paradigm under development. In: D. Euler \& P. F. E. Sloane (Hg.): Design-Based Research, Bd. 27. 1. Aufl. Stuttgart: Franz Steiner Verlag (Beihefte Zeitschrift für Berufs- und Wirtschaftspädagogik, Bd. 27), $15-44$.

Euler, D. (2016). Soziale Kompetenz-allseits gefordert, wenig erforscht... In: Zeitschrift für Berufs- und Wirtschaftspädagogik 112 (4), 517-524.

Euler, D., \& Bauer-Klebl, A. (2009). Sozialkompetenzen in der beruflichen Bildung. 1. Ed., Bern [u.a.]: Haupt.

Faix, W. G., \& Laier, A. (1996). Soziale Kompetenz. Wettbewerbsfaktor der Zukunft. Wiesbaden: Gabler Verlag.

Gessler, M., \& Kühn, K. (2013). Werkschulen in Bremen - ein präventiver Ansatz zur Integration lernbenachteiligter Jugendlicher. In: Zeitschrift für Berufs- und Wirtschaftspädagogik 109 (2), 262-277. 
Gudjons, H. (2008). Handlungsorientiert lehren und lernen: Schüleraktivierung Selbsttätigkeit - Projektarbeit. 7., Ed.; Bad Heilbrunn: Klinkhardt.

Hinsch, R., \& Pfingsten, U. (2007). Gruppentraining sozialer Kompetenzen: GSK. Grundlagen, Durchführung, Anwendungsbeispiele. 5., Ed. Weinheim [u.a.]: Beltz, PVU.

Jerusalem, M., Drössler, S., Kleine, D., Klein-Heling, J., Mittag, W., \& Röder, B. (2009). Förderung von Selbstwirksamkeit und Selbstbestimmung im Unterricht. Skalen zur Erfassung von Lehrer- und Schülermerkmalen. Lehrstuhl für Pädagogische Psychologie und Gesundheitspsychologie (Hg.). Humboldt-Universität zu Berlin. Retrieved from https://www.erziehungswissenschaften.hu-berlin.de/de/paedpsych/for schung/Skalenbuch_FoSS.pdf

Jugert, G., Rehder, A., Notz, P., \& Petermann, F. (2010). Fit for Life. Module und Arbeitsblätter zum Training sozialer Kompetenz für Jugendliche. 8. Ed.; Weinheim, Basel: Beltz Juventa.

Kang, S.-M., Day, J. D., \& Meara, N. M. (2006). Soziale und emotionale Intelligenz: Gemeinsamkeiten und Unterschiede. In: R. SCHULZE, F. A. FREUND \& R. D. ROBERTS (Hg.): Emotionale Intelligenz: Ein internationales Handbuch, 101-115. Göttingen: Hogrefe Verlag.

Kanning, U. P. (2002). Soziale Kompetenz. Definition, Strukturen, Prozesse. In: Zeitschrift für Psychologie 210 (4), 154-163.

Kiper, H., \& Mischke, W. (2008). Selbstreguliertes Lernen, Kooperation, soziale Kompetenz. Stuttgart: Verlag W. Kohlhammer.

Klieme, E., \& Hartig, J. (2007). Kompetenzkonzepte in den Sozialwissenschaften und im erziehungswissenschaftlichen Diskurs. In: Zeitschrift für Erziehungswissenschaft, Sonderheft (Bd. 8), 11-29.

Kramer, K., Prenzel, M., \& Drechsel, B. (2000). Lernmotivation in der kaufmännischen Ausbildung aus der Perspektive von Auszubildenden unterschiedlicher Berufe. In: Zeitschrift für Berufs- und Wirtschaftspädagogik 96 (2).

Kultusministerkonferenz (KMK) (1996, 2007, 2011). Handreichungen für die Erarbeitung von Rahmenlehrplänen der Kultusministerkonferenz für den berufsbezogenen Unterricht in der Berufsschule und ihre Abstimmung mit Ausbildungsordnungen des Bundes für anerkannte Ausbildungsberufe. Sekretariat der ständigen Konferenz der Kultusminister der Länder in der Bundesrepublik Deutschland $(\mathrm{Hg})$. Bonn. Retrieved from http://www.kmk.org/fileadmin/Dateien/veroeffentlichungen_beschlues se/2007/2007_09_01-Handreich-Rlpl-Berufsschule.pdf

McKenney, S. E., \& Reeves, T. C. (2012). Conducting Educational Research Design. What, Why and How. Hoboken: Taylor \& Francis.

Merrill, K. L., Smith, S. W., Cumming, M. M., \& Daunic, A. P. (2017). A Review of Social Problem-Solving Interventions. Past Findings, Current Status, and Future Directions. In: Review of Educational Research, 87(1), 71-102. doi:10.3102/0034654316652943 
Monnier, M. (2015). Difficulties in Defining Social-Emotional Intelligence, Competences and Skills - a Theoretical Analysis and Structural Suggestion. In: International Journal for Research in Vocational Eucation and Training (IJRVET), 2(1), 59-84. doi:10.13152/IJRVET.2.1.4

Möbus, A.-K. (2013). Die Förderung sozialer Kompetenz mittels kooperativer Lehr- und Lernformen. Retrieved from https://kobra.bibliothek.uni-kassel.de/bitstream/urn:n bn:de:hebis:34-2014020544947/5/MoebusFoerderungSozialerKompetenzen.pdf

Neubert, A. (2009). Leitkategorie: soziale Kompetenz. Konsequenzen einer Analyse beruflicher Komplexität aus systemtheoretischer Perspektive. Frankfurt am Main [u.a.]: Lang (Europäische Hochschulschriften - Reihe XI, 989).

OECD (2015). Skills for Social Progress. OECD Publishing. doi $10.1787 / 23078731$

Oerter, R., \& Dreher, E. (2008). Jugendalter. In: R. Oerter \& L. Montada (Ed.): Entwicklungspsychologie. 6., vollst. überarb. Aufl. (p. 271-323). Weinheim, Basel: Beltz PVU.

Pekrun, R., \& Schiefele, U. (1996). Emotions- und motivationspsychologische Bedingungen der Lernleistung. In: F. E. Weinert, N. Birbaumer \& C. F. Graumann (Hg.): Psychologie des Lernens und der Instruktion: Praxisgebiete Ser. 1: Pädagogische Psychologie, Bd. 2; in: Enzyklopädie der Psychologie, 154-180. Göttingen [u.a.]: Hogrefe.

Schwartz, D.L., Chang, J., \& Martin, L. (2005). Instrumentation and Innovation in Design Experiments: Taking the Turn towards Efficiency. Stanford University. Internal Paper. Retrieved from https://pdfs.semanticscholar.org/f20d/940f10c2de6b99170ea b30fbe5db4034e369.pdf

Schonert-Reichl, K. A., \& Lawlor, M. S. (2010). The Effects of a Mindfulness-Based Education Program on Pre- and Early Adolescents Well-Being and Social and Emotional Competence. In: Mindfulness 1 (3), 137151. doi 10.1007/s12671-010-0011-8

Seeber, S., \& Wittmann, E. (2017). Social Competence Research: A Review. In: M. Mulder (Ed.): Competence-based Vocational and Professional Education. Bridging the Worlds of Work and Education (p.1029-1050). Cham: Springer International Publishing; Imprint: Springer Verlag.

Seligman, M. E. P., Ernst, R. M., Gillham, J., Reivich, K., \& Linkins, M. (2009). Positive education. Positive psychology and classroom interventions. In: Oxford Review of Education 35 (3), 293-311. doi:10.1080/03054980902934563

Straka, G. A., \& Macke, G. (2005). Lern-lehr-theoretische Didaktik. 3. Ed., Münster [u.a.]: Waxmann.

Taylor, A., Liang, B., Tracy, A. L., Williams, L. M., \& Seigle, P. (2002). Gender Differences in Middle School Adjustment, Physical Fighting, and Social Skills: Evaluation of a Social Competency Program. doi:10.1023/A:1019976617776

Weinert, F. E. (2001). Concept of competence: A conceptual clarification. In: D. S. Rychen und L. H. Salganik (Ed.): Defining and Selecting Key Competencies (p. 45-65). Seattle [u.a.]: Hogrefe \& Huber.

Wirtz, M. A., \& Caspar, F. (2007). Beurteilerübereinstimmung und Beurteilerreliabilität. Methoden zur Bestimmung und Verbesserung der Zuverlässigkeit von Einschätzungen mittels Kategoriensystemen und Ratingskalen. Göttingen [a.o.]: Hogrefe. 
Wolf, K. D. (2003). Gestaltung und Einsatz einer internetbasierten Lernumgebung zur Unterstützung Selbstorganisierten Lernens. Hamburg: Kovač.

Yeates, K. (1989). Social competence in the schools. Toward an integrative developmental model for intervention. In: Developmental Review 9 (1), 64-100. doi:10.1016/02732297(89)90024-5

\section{Biographical Notes}

Dr Ida Kristina Kühn is a research associate at the Institute Technology and Education (ITB) of the University of Bremen. Her research interest focuses on youth and dropout, transition system between school and work/apprenticeship, teaching and learning in adult and vocational education and Design-Based Research. 